\title{
Aggressive resection and outcomes of primary craniopharyngiomas via an endoscopic endonasal approach based on an anatomical sub-classification
}

Hiroki Morisako ( $\square$ hmorisako@med.osaka-cu.ac.jp )

Oaka City University Graduate School of Medicine https://orcid.org/0000-0003-2789-2232

Hiroki Ohata

Yuki Sakaeyama

Tsuyoshi Sasaki

Shugo Nishijima

Tsutomu Ichinose

Yuichi Teranishi

Kenji Ohata

Takeo Goto

\section{Research Article}

Keywords: craniopharyngioma, endoscopic endonasal approach, surgical management, clinical outcome, aggressive surgery, anatomical sub-classification

Posted Date: February 21st, 2022

DOI: https://doi.org/10.21203/rs.3.rs-1325867/v1

License: (c) (1) This work is licensed under a Creative Commons Attribution 4.0 International License.

Read Full License 


\section{Abstract}

Objective: The optimal treatment of patients with craniopharyngioma remains controversial. In recent years, we have removed tumors radically via an endoscopic endonasal approach (EEA) in all cases of primary craniopharyngioma. We present here our surgical strategy and outcomes of primary craniopharyngiomas via an EEA.

Methods: Between 2015 and 2021, we resected 37 consecutive cases of primary craniopharyngioma via EEA. Aggressive resections had been originally planned in all cases. To help choose the adequate surgical management, we created the five groups included the intrasellar, prechiasmatic, retrochiasmatic, intra- $3^{\text {rd }}$ ventricle and large lobulated type. Bony removal of the dorsum sellae, upper clivus and posterior clinoid process was added in cases with retrochiasmatic or third ventricular lesions, and a combination of EEA and transcranial approach was selected with large multi-lobulated tumors and lateral extension.

Results:

16 tumors were classified as retrochiasmatic, 12 tumors as intra- $3^{\text {rd }}$-ventricle, 4 tumors as prechiasmatic, 3 tumors as large lobulated, and 2 tumors as intrasellar type. Gross total resection (GTR) was achieved in $89.2 \%$, near-total resection (NTR) in $8.1 \%$, and subtotal resection (STR) in $2.7 \%$. The pituitary stalk was preserved intraoperatively in $27.0 \%$. Visual improvement was noted in $76.7 \%$. Neuropsychological function status was improved or preserved in all cases. Tumor recurrence was detected $3.0 \%$ of GTR, $33.3 \%$ of 3 NTR and $100 \%$ of STR cases with the mean follow-up period of 32.7 months.

Conclusion: Adequate surgical management according to the anatomical location of the lesion via EEA results in good visual and cognitive outcomes with increased extent of resection.

\section{Introduction}

Craniopharyngioma is a histologically benign tumor arising in the sellar and suprasellar region along the path of the craniopharyngeal duct. Craniopharyngioma is diagnosed either in childhood or adulthood due to local mass effects on visual pathways, the pituitary and the hypothalamus, or because of increased intracranial pressure resulting from obstructive hydrocephalus. Despite the benign appearance, this pathological entity has been associated with unfavorable prognosis, due to the proximity to and relationships with vital structures $[3,8,15]$.

The optimal treatment of patients with craniopharyngioma remains controversial, because protocols effectively balancing aggressive therapy with minimal adverse symptoms remain lacking for both children and adults $[6,9,11,16,20,22,29,35]$. Complete tumor resection is associated with the best outcomes in terms of overall and recurrence-free survival. Nevertheless, the location and frequent involvement of critical neurovascular structures, tumor size, calcifications, and age at presentation may limit the extent of resection. Radical resection is associated with risks of significant morbidity in terms of visual, hypothalamic, and endocrinological disturbances, potentially deteriorating quality of life for 
patients $[8,31]$. For these reasons, some neurosurgeons advocate a less aggressive surgical treatment followed by radiation therapy.

In recent years, endoscopic endonasal surgery has become the main surgical approach for craniopharyngiomas $[17,25,27]$. Radical tumor resection has been our treatment policy for craniopharyngiomas and recent tumors have been removed by EEA as the initial treatment for all cases of primary craniopharyngioma. This report describes our surgical strategy based on the anatomical subclassification for resecting craniopharyngioma via the EEA, and provides our surgical outcomes for primary craniopharyngioma.

\section{Methods}

Between 2015 and 2021, Osaka City University Hospital performed surgical resection via EEA as initial treatment for 37 consecutive patients with primary craniopharyngioma. Patients who underwent surgery or radiation therapy prior to this endoscopic endonasal surgery were not included in the present analysis. All cases included in this study were retrospectively analyzed using electronic medical records. Patients comprised 15 males and 22 females with a mean age of 46.8 years (range, 5-80 years). Mean tumor diameter was $27.1 \mathrm{~mm}$ (range, $15-78 \mathrm{~mm}$ ). Table 1 shows the characteristics and detailed clinical information of patients.

All patients underwent preoperative imaging using CT and MRI to assess and identify tumor location, tumor extent, ventricular size, and neurovascular location. Ophthalmological evaluations included visual acuity and visual fields. Endocrinological status was evaluated and anterior pituitary hormone dysfunction was defined as the use of hormone supplementation or the presence of high levels of prolactin without the use of dopamine agonists. Diabetes insipidus was diagnosed before and after surgery based on the sodium level and presence of hypotonic polyuria. Cognitive function was assessed pre- and postoperatively. A patient was considered to show cognitive impairment if any of the following conditions were met: 1) Mini-Mental State Examination score $<20$ or 2) the patient felt unable to continue previous profession due to the presence of the lesion. BMI (Body Mass Index) was measured in all patients before and after surgery to evaluate obesity. For each patient, Karnofsky Performance Scale (KPS) was retrospectively reviewed through the medical records.

Tumor volume was measured using 3-dimensional contrast-enhanced MRI at a workstation (SynapseVincent, FUJIFILM Medical Co., Ltd.), and the extent of tumor resection achieved was calculated using MRI data from preoperatively and 1 week postoperatively. Gross total resection (GTR) was defined as the absence of residual lesions or residual calcification. Near-total resection (NTR) was defined as residual lesion or calcification $<0.5 \mathrm{~cm}^{3}$. Subtotal resection (STR) was defined as a residual lesion or calcification $\geq 0.5 \mathrm{~cm}^{3}$. Follow-up MRI was performed at regular intervals within 1 week and 3 months after surgery, and again after 6-12 months. Tumor recurrence during follow-up was defined as the appearance of a new lesion on MRI or the growth of residual tumor. 
In addition, we investigated historical changes in surgical procedures and outcomes for craniopharyngioma at a single institute. Patients were divided into two groups for comparison based on the timing of surgery: a previous treatment group $(n=28)$, with patients between 2009 and 2014 treated mainly using several microscopic transcranial approaches, and a recent treatment group $(n=37)$, with patients between 2015 and 2021 treated mainly via EEA.

\section{Surgical strategies}

Craniopharyngiomas were classified based on location, origin, and preoperative growth pattern. The five groups defined in our classification scheme and used to select the appropriate surgical management were intrasellar, prechiasmatic, retrochiasmatic, intra-third ventricle, and large lobulated types (Fig 1). Intrasellar-type craniopharyngioma originates from the intrasellar part of the pituitary stalk. With this lesion type, the sellar floor is usually enlarged in a manner similar to that seen in pituitary adenoma. The prechiasmatic type originates from the anterior part of the stalk and grows in an upward direction. Upward elevation of the optic chiasm and anterior communicating artery is also seen, with the tumor extending laterally. Retrochiasmatic-type craniopharyngioma originates from the posterior part of the pituitary stalk and grows up toward the posterior fossa. The optic chiasm and anterior communicating artery remain in their normal positions. The intra-third ventricle type originates from the floor of the third ventricle. Finally, multi-lobular tumors over $4 \mathrm{~cm}$ in diameter are defined as the large lobulated type.

The basic surgical procedure via EEA is as follows. First, a nasoseptal mucosal flap is harvested. The sphenoid sinus and posterior ethmoid sinus are opened widely, then the tuberculum sellae and sella turcica are drilled out. For prechiasmatic-type lesions, the planum sphenoidale and medial inferior wall of the optic canal are also removed. For retrochiasmatic, intra-third ventricle, or large lobulated lesions, additional removal of the dorsum sellae, upper clivus and posterior clinoid process is performed, and the pituitary gland is detached from the medial wall of the cavernous sinus and transposed from one side to the other for complete exposure of the lesion. Furthermore, for large blobulated-type lesions with lateral extension beyond the internal carotid artery (ICA), oculomotor nerve, and posterior communicating ( $P$ com) artery, combined surgery with EEA and a transcranial approach is selected. The pituitary stalk is preserved if allowed by its positional relationship with the tumor. If the tumor is found to be tightly adherent to the optic pathway, hypothalamus, or arteries including small perforating arteries from the ICA or P-com artery, tumor resection is stopped. Skull base reconstruction involves multi-layered reconstruction to prevent leakage of cerebrospinal fluid (CSF).

Figure 1 shows our surgical strategy for craniopharyngioma via EEA based on the anatomical subclassification.

\section{Illustrative Cases}

Case 1: Intrasellar type 
An intrasellar lesion was detected in an 15-year-old boy suffering from visual dysfunction. Preoperative CT and MRI demonstrated characteristic findings of the intrasellar type of craniopharyngioma (Fig 2A-C). The bone was removed from the sellar floor to the tuberculum sellar (Fig 2F). The tumor was then carefully dissected off any adjacent critical neurovascular structures (Fig $2 \mathrm{G}, \mathrm{H}$ ) and totally removed with preserving pituitary gland and stalk (Fig 2D,E,I). Postoperatively, anterior pituitary function was maintained.

\section{Case 2: Prechiasmatic type}

A 44-year-old female exhibiting a deterioration of her visual acuity on the right side was referred to our hospital. Preoperative CT and MRI demonstrated there was elevation of the optic chiasm and anterior communicating artery (Fig 3A-C). The bone was removed from the sellar floor to planum sphenoidale and medial inferior wall of the optic canal are also removed (Fig 3F). After displacing the normal pituitary gland (Fig $3 G, H)$, the tumor capsule was peeled from the stalk and optic chiasm (Fig 3l,J). The tumor was totally removed with preserving the stalk (Fig 3E,F,K). Postoperatively, visual dysfunction improved and anterior and posterior pituitary function were maintained.

Case 3: Retrochiasmatic type (Video 1)

Retrochiasmatic-type craniopharyngioma with hydrocephalus was identified in a 5-year-old girl with headache, vomiting and bitemporal hemianopsia (Fig 4A-D). After bone removal from the bottom of the sella turcica to the tuberculum sellae, the upper clivus, dorsum sellae and bilateral posterior clinoid processes were removed (Fig $4 \mathrm{H})$. Tumor in the retrochiasmatic region was confirmed after displacing the normal pituitary gland (Fig 4I). After internal decompression of the tumor, the tumor was detached from the optic chiasm, perforating arteries branching off the ICA and P-com artery (Fig $4 \mathrm{~J}$ ). The boundary of the wall of third ventricular was confirmed (Fig 4K). As a result, complete removal of the tumor was achieved (Fig 4E-G,L,M). Improvement of neurological symptoms was observed postoperatively. She started anterior and posterior pituitary hormone replacement therapy and is currently living a normal life without any problems.

Case 4: Intra-third ventricle type

An intra-third ventricle craniopharyngioma with hydrocephalus was identified in a 20-year-old man (Fig $5 A-C)$. After bone removal from the bottom of the sella turcica to the tuberculum sellae, additional bony removal of the dorsum sellae, upper clivus and bilateral posterior clinoid processes was performed (Fig $5 F$ ). The tumor developed continuously to the infundibular recess. Therefore, preservation of the pituitary stalk was judged likely to prove difficult, so the stalk was cut (Fig 5G). An incision was made in the tumor and internal decompression of the tumor was initiated (Fig $5 \mathrm{H}$ ). The boundary of the wall of the third ventricle was confirmed (Fig 5I). After grasping and peeling only the tumor capsule from the wall of the third ventricle, the tumor was completely removed (Fig $5 E, F, J, K)$.

Case 5: Large lobulated type with lateral extension (Video 2) 
A 5-year-old girl presented with a history of worsening visual dysfunction for a few months and recent right oculomotor nerve palsy. Intracranial images showed a large, lobulated craniopharyngioma with lateral extension (Fig 6A-D). Combined surgery with EEA and a microscopic transcranial approach was applied to completely remove the tumor, including the tumor capsule, in a single stage. After bone removal from the sella turcica to the tuberculum sellae, additional bony removal of the dorsum sellae, upper clivus and bilateral posterior clinoid processes was performed via EEA (Fig 6H). After the pituitary gland was displaced to the left, the lesion inside the circle of Willis was removed while detaching the tumor and pituitary stalk (Fig $6 \mathrm{I}$ ). At the same time, after frontotemporal craniotomy (Fig $6 \mathrm{~J}$ ), the tumor capsule was detached from the deep Sylvian vein and brain surface, and gradually dropped toward the sellar area via a transcranial approach (Fig 6K). After removal of the posterior component of the tumor, the hypothalamus and brainstem were decompressed via EEA (Fig $6 \mathrm{~L}$ ). Finally, the tumor was completely removed with preservation of the pituitary stalk (Fig 6E-G,M). Postoperatively, oculomotor nerve palsy and visual dysfunction improved, and anterior pituitary function was maintained.

\section{Results}

Tables 1 shows summary of the clinical data and surgical outcomes of 37 patients with primary craniopharyngiomas resected via EEA based on an anatomical sub-classification.

\section{Characteristics of lesions}

Lesion classification was retrochiasmatic in 16 cases, intra-third ventricle in 12 cases, prechiasmatic in 4 cases, large lobulated in 3 cases, and intrasellar in 2 case. EEA was used in all cases, and combination with the transcranial approach was applied for 2 cases of large lobulated type with lateral extension. With combined surgery, one of the cases underwent EEA and a frontotemporal approach at the same time, and in the other, the subfrontal approach was performed as a second-stage surgery following the initial EEA.

\section{Extent of resection}

The degree of tumor resection was judged as GTR in 33 of 37 cases, NTR in 3 cases, and STR in 1 case. In a 80 year-old patient with retrochiasmatic lesion, near-total tumor resection was achieved to preserve of normal pituitary stalk. In one middle age patient with retrochiasmatic lesion, small piece of tumor remained due to the severe adhesion with left posterior cerebral artery. In one middle age patient with a large lobulated lesion with lateral extension, tumor remained in the cavernous sinus, so NTR was achieved and stereotactic irradiation was added 3 months after tumor resection. In a 74-year old patient with large lobulated lesion without lateral extension, tumor remained around the hypothalamus and foramen of Monro, resulting in STR.

\section{Surgical complications}

No surgery-related deaths occurred. No permanent cranial nerve palsies were seen. Postoperative CSF leakage was observed in 2 of 37 cases (5.4\%), necessitating repair surgery. Postoperative hemorrhage 
was observed in 1 of 37 cases (2.7\%), necessitating hematoma removal, but cognitive function was preserved at the recent follow-up.

\section{Visual and cognitive function}

Visual function was seen to be affected in 30 cases (81.1\%) before surgery, and improved after surgery in 23 cases with visual symptoms $(76.7 \%)$, and was unchanged in the remaining cases, with no patients experiencing deterioration. Cognitive dysfunction was observed in 9 cases $(24.3 \%)$ before surgery, and improved after surgery in 8 cases with cognitive impairment (88.9\%), remained unchanged in the other cases, and showed worsening in no cases.

\section{Pituitary function}

Preoperative dysfunction of the anterior pituitary was observed in 32 cases (86.5\%), and posterior pituitary dysfunction was observed in 3 cases $(8.1 \%)$. The pituitary stalk was able to be preserved intraoperatively in 10 cases $(27.0 \%)$, and postoperative function of the anterior pituitary was maintained in 3 of these 10 cases $(30.0 \%)$, and posterior pituitary function was maintained in 4 of 10 these cases (40.0\%). Postoperatively, replacement therapy for anterior pituitary hormone was required in 34 patients (91.2\%), and diabetes insipidus was observed in 33 patients (89.2\%).

Obesity

Preoperative BMI ranged from 25 to 29 in 3 patients (8.1\%) and 1 patient $(2.7 \%)$ was 30 or higher. Postoperative BMI ranged from 25 to 29 in 7 patients (18.9\%) and no patient showed postoperative BMI of 30 or higher at last follow-up.

\section{Tumor recurrence and local control}

Regarding local control of tumors, recurrence was observed in 3 of 37 patients (8.1\%) with a mean followup period of 32.7 months (range, 2-84 months). Recurrence was seen 1 of the 33 patients with GTR (3.0\%), as well as in the one patient of 3 with NTR (33.3\%) and the patient with STR (100\%). For recurrent cases, EEA was performed again for 1 case with recurrence after GTR. One patient who achieved NTR with SRS showed recurrence after 1.5 years and re-SRS was performed. In a 74-year old patient with resulting in STR, MIB-1 labeling index of the tumor was 33.4\%, and re-growth of residual tumor was observed 2 weeks after surgery. KPS of this patient was 30 , so we judged that neither re-excision nor additional radiotherapy were indicated. Regular image follow-up is being performed every 3-6 months, and local control of lesions has currently been obtained in 36 cases, excluding the 1 case showing STR.

Histological changes of the surgical procedures and outcomes at a single institute

Table 2 shows a comparison of surgical procedures and outcomes according to the treatment period. In the previous treatment group (2009-2014), 28 cases of primary craniopharyngioma were resected, and the surgical approach was interhemispheric in 14 cases, frontotemporal in 13 cases, transsphenoidal in 8 
cases, and transpetrosal in 4 cases. Multi-staged surgery was performed in 11 cases (39.3\%), with GTR achieved in $67.9 \%$ and NTR in $32.1 \%$. In the recent treatment group (2015-2021), in which EEA was performed in all cases, the transcranial approach was used in only 2 cases, and multi-staged surgery was applied in 1 case (3.2\%). GTR was achieved in 33 cases (89.2\%). Comparing the previous and recent treatment groups, the total number of operations required for radical resection was decreased and the extent of tumor resection was increased in the recent treatment group. Furthermore, the improvement rate of postoperative KPS and clinical outcomes were even better in the recent treatment group.

\section{Discussion}

Craniopharyngioma can be cured by total removal of the tumor, so surgical resection is the first choice of treatment $[8,11,15,22]$. However, complete removal of the tumor without aggravating clinical symptoms is not easy. Some reports have described treatment policies that combine partial excision with radiation therapy or stereotactic radiation surgery to reduce surgical complications $[3,6,21,32,35]$. On the other hands, some patients show problems such as tumor regrowth after irradiation or worsening of visual field impairments due to radiation $[19,30]$. In many cases of recurrence, complete tumor removal is more difficult than in the first surgery. As a result, there are cases in which recurrence is repeated and local control of the tumor proves difficult. In the course of repeated treatment, not only hypopituitarism, but also severe visual dysfunction and decreased memory ability are observed. We have thus traditionally treated primary craniopharyngiomas using a policy of aggressive tumor resection without causing memory disorders or visual impairment, even if pituitary function is sacrificed [15, 22]. Since craniopharyngioma is basically located inside the circle of Willis, the transcranial approach has been problematic when tumor is dissected from perforating branches of the ICA or P-com artery from outside of the circle of Willis. EEA allows entry to the circle of Willis from the sella turcica. Tumor removal with safe peeling from the penetrating arteries represents an advantage. The third ventricular wall can also be observed directly, so EEA has become the main surgical approach for craniopharyngioma in recent years $[17,25,27]$.

\section{Role of anatomical sub-classification of craniopharyngioma for appropriate surgical management in EEA}

Craniopharyngioma can occur from any site along the pituitary stalk, so the tumor can appear the same as suprasellar tumor, but due to slight differences in the origin, positional relationships differ between the tumor and structures such as the optic chiasm, hypothalamus, anterior cerebral artery and pituitary gland. We therefore consider it useful to examine the extent of bone removal according to the tumor origin, and so applied anatomical subclassifications of craniopharyngioma to guide the surgical strategy (Fig. 1).

The intrasellar type can be removed in the same manner as pituitary adenoma. The prechiasmatic type shows a wide distance between the pituitary gland and optic chiasm, because the optic chiasm is raised upward, and removed safely. On the other hand, the optic chiasm is not elevated upward in cases of retrochiasmatic or intra-third ventricle type, and no working space exists between the optic chiasm and 
sella turcica. Further removal of the dorsum sellae and posterior clinoid processes allows wide exposure of these lesions. In particular, for lesions that have progressed to the third ventricle, an advantage is present in that the hypothalamus can be detached relatively safely because the floor of the third ventricle can be observed directly under the angled endoscope. EEA has recently basically represented the first choice for any type of craniopharyngioma. For large lobular lesions that extend laterally beyond the circle of Willis and each cranial nerve, we believe that a combination of EEA and transcranial approaches is needed. Whether EEA and transcranial approaches are performed in one or two stages is determined by the nature of the lesion. Compared to solid tumors, two-stage resection of a cystic tumor is more likely to leave tumor behind by loss of tumor capsule during the second tumor resection. For this reason, we plan a one-stage removal, especially for large, cystic, lobular lesions. Comparing the previous treatment group (2009-2014) and the recent treatment group (2015-2021), the number of cases requiring multi-staged removal decreased and better surgical results were obtained in the recent treatment group. In EEA, the caudal surface of the optic chiasm, the bottom of the third ventricle and the hypothalamus can be observed in close proximity, so meticulous resection of the tumor, including the tumor capsule, can be safely performed.

\section{Surgical outcomes for craniopharyngioma}

Regarding the extent of tumor resection, a higher removal rate has been reported in recent years with EEA compared to the transcranial approach $[18,34]$. In our series, GTR was possible in $89.2 \%$, and the extent of tumor resection was improved compared to the previous treatment group, which mainly used transcranial approaches. The incidence of postoperative CSF leakage as a complication of EEA with intraoperative high-flow CSF leakage has been reported as $4.8-10 \%[4,24]$. We encountered postoperative CSF leakage requiring repair surgery in two cases (5.4\%). Reconstruction is performed by filling the sella turcica with pieces of free fat, performing dural suturing, then covering the skull base widely using a nasal septal mucosal flap, and the incidence of postoperative CSF has been kept low. Regarding pituitary function, panhypopituitarism was observed in $57-98 \%$ and diabetes insipidus in $64-$ $80 \%$ during the course of treatment $[1,2,13,14,28,33]$. Endocrine function in long-term follow-up after treatment for craniopharyngioma showed hypopituitarism in about $90 \%$ of those patients followed-up for $\geq 10$ years regardless of whether treatment was performed with total excision, partial excision, partial excision or radiation therapy [33]. One report found that $12 \%$ were able to maintain normal pituitary function even when the pituitary stalk was morphologically preserved [26]. We preserved the pituitary stalk morphologically in 10 of 37 cases (27.0\%), maintained anterior pituitary function in 3 of these 10 cases $(30.0 \%)$, and maintained posterior pituitary function in 4 of these 10 cases $(40.0 \%)$ at last followup. In our series, the retrochiasmatic, intra-third ventricle or large lobulated types, in which blood flow in the pituitary stalk is more difficult to preserve, accounted for 31 of 37 cases $(83.8 \%)$. We believe that the positional relationship between tumorigenesis and the pituitary stalk is the most important for preserving pituitary function. For this reason, particularly in young cases, we strive to preserve the stalk if possible according to the positional relationship between the tumor and pituitary stalk. Priority is given to tumor removal regardless of the preservation of pituitary function to avoid tumor recurrence and additional radiation therapy. Hypothalamic disorders reportedly occur in $65-80 \%$ after surgery, and obesity occurs in 
$40-80 \%$ after surgery $[7,10,12,28,33,36]$. Preoperative visual impairment is reportedly improved in $75-$ $100 \%$ of cases after surgery $[13,14,36]$. Our series included no cases of severe obesity, and no worsening of visual impairment or cognitive function. As a result, pituitary function is sacrificed, but the lesion can be resected aggressively without incurring cognitive disorders or visual dysfunction.

The rate of tumor recurrence depends on the extent of tumor resection, and the recurrence rate in GTR cases is reported as $10-20 \%[5,6,12,22,23]$. Our experience identified extent of tumor resection and MIB-1 labeling index as factors independently associated with local recurrence [22]. Regarding the addition of radiation therapy, no difference in tumor control has been reported between cases of GTR and cases of PR with added radiation $[6,35]$. Recent results from radiation therapy have achieved tumor control rates of $97-100 \%$ with fractionated irradiation, but follow-up periods have often been less than 5 years $[3,21]$. Some papers reporting long-term results after radiation have described tumor control rates of about $50 \%$ at 200 months $[19,30]$. At present, therefore, irradiation is considered effective for shortterm tumor control. In our cases, recurrence was seen in 1 of the 33 cases (3.0\%) with GTR, and reexcision was performed. One patient who achieved NTR with SRS showed recurrence after 1.5 years and re-SRS was performed. One patient who only achieved STR showed very high tumor growth potential and local control of the tumor was not possible. As a result, local control of lesions was obtained in 36 cases $(97.3 \%)$ at latest follow-up, excluding the 1 case of STR.

Therefore, as a basic treatment policy for craniopharyngioma, we remove the lesion aggressively without causing cognitive disorder or visual impairment by EEA. Radical resection of the tumor at the time of initial treatment is important for long-term tumor control, particularly in young patients. If tumor remains around arteries, optic pathway or hypothalamus, residual tumor is followed-up carefully. Since the followup period of the present study was short, further follow-up is considered necessary to determine long-term tumor control.

\section{Conclusion}

Radical resection of craniopharyngioma has traditionally been associated with significant morbidity and mortality. Advances in endoscopic surgery techniques and skull base approaches in combination have significantly improved surgical outcomes and facilitated radical resection. EEA for craniopharyngioma offers the advantage that the tumor origin, hypothalamus, and lower surface of the optic chiasm are easily observed. EEA is useful not only for intrasellar and prechiasmatic craniopharyngiomas, but also for retrochiasmatic and intra-third ventricular craniopharyngiomas, and can safely and aggressively resect lesions. On the other hand, in the case of large lobulated lesions in which the tumor extends laterally beyond the circle of Willis, a combination of EEA and transcranial approach is useful for further aggressive tumor resection.

\section{Declarations}

\section{Acknowledgements and Conflict of Interest}


No funds were received in support of this work. No benefits in any form have been or will be received from a commercial party related directly or indirectly to the subject of this manuscript.

\section{Funding}

The authors declare that no funds, grants, or other support were received during the preparation of this manuscript.

\section{Conflicts of interest/Competing interests}

The authors have no relevant financial or non-financial interests to disclose.

\section{Availability of data and material}

Not applicable

\section{Code availability (software application or custom code)}

Not applicable

\section{Ethics approval}

This study was performed in line with the principles of the Declaration of Helsinki. Approval was granted by the Ethics Committee of Osaka City University(No2020-098).

\section{Consent to participate}

Informed consent was obtained from all individual participants (or their parent or legal guardian in the case of children under 16) included in the study.

\section{Consent to publication}

The authors affirm that human research participants provided informed consent for publication of the images in Figure(s) 2,3,4,5,6 and Video 1,2.

\section{Authors' Contributions}

All authors contributed to the study conception and design. Material preparation, data collection and analysis were performed by Hiroki Morisako, Hiroki Ohata, Yuki Sakaeyama, Tsuyoshi Sasaki, Shugo Nishijima, Tsutomu Ichinose, Yuichi Teranishi, Kenji Ohata, and Takeo Goto. The first draft of the manuscript was written by Hiroki Morisako and all authors commented on previous versions of the manuscript. All authors read and approved the final manuscript.

\section{References}


1. Bakhsheshian J, Jin DL, Chang KE, et al (2016) Risk factors associated with the surgical management of craniopharyngiomas in pediatric patients: analysis of 1961 patients from a national registry database. Neurosurg Focus 41: E8. DOI: 10.3171/2016.8.FOCUS16268

2. Chivukula S, Koutourousiou M, Snyderman $\mathrm{CH}$, et al (2013) Endoscopic endonasal skull base surgery in the pediatric population. J Neurosurg Pediatr 11:227-241. DOI: 10.3171/2012.10.PEDS12160

3. Combs SE, Thilmann C, Huber PE,Hoess A, Debus J, Schulz-Ertner D (2007) Achievement of longterm local control in patients with craniopharyngiomas using high precision stereotactic radiotherapy. Cancer 109:2308-2314. DOI: 10.1002/cncr.22703.

4. Conger A, Zhao F, Wang X, et al (2018) Evolution of the graded repair of CSF leaks and skull base defects in endonasal endoscopic tumor surgery: trends in repair failure and meningitis rates in 509 patients. J Neurosurg 130:861-875. DOI: 10.3171/2017.11.JNS172141

5. Di Rocco C, Caldarelli M, Tamburrini G, et al (2006) Surgical management of craniopharyngiomas experience with a pediatric series. J Pediatr Endocrinol Metab 19:355-366.

6. Duff JM, Meyer FB, Ilstrup DM, et al (2000) Long-term outcomes for surgically resected craniopharyngiomas. Neurosurgery 46:291-302. DOI: 10.1097/00006123-200002000-00007.

7. Elliott RE, Hsieh K, Hochm T, et al (2010) Efficacy and safety of radical resection of primary and recurrent craniopharyngiomas in 86 children. J Neurosurg Pediatr 5:30-48. DOI: 10.3171/2009.7.PEDS09215

8. Fahlbusch R, Honegger J, Paulus W, Huk W, Buchfelder M (1999) Surgical treatment of craniopharyngiomas: experience with 168 patients. J Neurosurg 90:237-250. DOI: 10.3171/jns.1999.90.2.0237.

9. Greenfield BJ, Okcu MF, Baxter PA,et al (2015) Long-term disease control and toxicity outcomes following surgery and intensity modulated radiation therapy (IMRT) in pediatric craniopharyngioma. Radiother Oncol 114:224-229. DOI: 10.1016/j.radonc.2014.11.035

10. Harrington MH, Casella SJ (2012) Pituitary tumors in childhood. Curr Opin Endocrinol Diabetes Obes 19:63-67. DOI: 10.1097/MED.0b013e32834ed6b9

11. Hoffman HJ, De Silva M, Humphreys RP, et al (1992) Aggressive surgical management of craniopharyngiomas in children. J Neurosurg 76:47-52. DOI: 10.3171/jns.1992.76.1.0047

12. Karavitaki N, Brufani C, Warner JT, et al (2005) Craniopharyngiomas in children and adults: systematic analysis of 121 cases with long-term follow-up. Clin Endocrinol 62:397-409. DOI: 10.1111/j.1365-2265.2005.02231.x

13. Koutourousiou M, Gardner PA, Fernandez-Miranda JC,et al (2013) Endoscopic endonasal surgery for craniopharyngiomas: surgical outcome in 64 patients. J Neurosurg 119:1194-1207. DOI: 10.3171/2013.6.JNS122259

14. Kshettry VR, Do H, Elshazly K, et al (2016) The learning curve in endoscopic endonasal resection of craniopharyngiomas. Neurosurg Focus 41: E9. DOI: 10.3171/2016.9.FOCUS16292

15. Kunihiro N, Goto T, Ishibashi K, Ohata K (2014) Surgical outcomes of the minimum anterior and posterior combined transpetrosal approach for resection of retrochiasmatic craniopharyngiomas 
with complicated conditions. J Neurosurg 120:1-11. DOI: 10.3171/2013.10.

16. Lin LL, El Naqa I, Leonard JR, et al (2008) Long-term outcome in children treated for craniopharyngioma with and without radiotherapy. J Neurosurg Pediatr 1:126-130. DOI: 10.3171/PED/2008/1/2/126

17. Liu JK, Sevak IA, Carmel PW, et al (2016) Microscopic versus endoscopic approaches for craniopharyngiomas: choosing the optimal surgical corridor for maximizing extent of resection and complication avoidance using a personalized, tailored approach. Neurosurg Focus 41:E5. DOI: 10.3171/2016.9.FOCUS16284

18. Madsen PJ, Buch VP, Douglas JE, et al (2019) Endoscopic endonasal resection versus open surgery for pediatric craniopharyngioma: comparison of outcomes and complications. J Neurosurg Pediatr 7:1-10. DOI: 10.3171/2019.4.PEDS18612

19. Masson-Cote L, Masucci GL, Atenafu EG, et al (2013) Long-term outcomes for adult craniopharyngioma following radiation therapy.Acta Oncol 52:153-158. DOI:

10.3109/0284186X.2012.685525

20. Merchant TE, Kiehna EN, Sanford RA, et al (2002) Craniopharyngioma: the St. Jude Children's Research Hospital experience 1984-2001. Int J Radiat Oncol Biol Phys 53:533-542. DOI: 10.1016/s0360-3016(02)02799-2

21. Minniti G, Saran F, Traish D, et al (2007) Fractionated stereotactic conformal radiotherapy following conservative surgery in the control of craniopharyngiomas. Radiother Oncol 82:90-95. DOI: 10.1016/j.radonc.2006.11.005

22. Morisako H, Goto $\mathrm{T}$, Goto $\mathrm{H}$,et al (2016) Aggressive surgery based on an anatomical subclassification of craniopharyngiomas. Neurosurg Focus 41:E10. DOI: 10.3171/2016.9.FOCUS16211

23. Mortini P, Losa M, Pozzobon G, et al (2011) Neurosurgical treatment of craniopharyngioma in adults and children: early and long-term results in a large case series. J Neurosurg 114:1350-1359. DOI: 10.3171/2010.11.JNS10670

24. Ogiwara T, Nagm A, Hasegawa T,et al (2019) Pitfalls of skull base reconstruction in endoscopic endonasal approach. Neurosurg Rev 42:683-689. DOI: 10.1007/s10143-018-1006-5

25. Ohata H, Goto T, Nagm A, Kannepalli NR, Nakajo K, Morisako H, Goto H, Uda T, Kawahara S, Ohata K (2019) Surgical implementation and efficacy of endoscopic endonasal extradural posterior clinoidectomy. J Neurosurg.3:1-9. DOI: 10.3171/2019.2.JNS183278

26. Ordóñez-Rubiano EG, Forbes JA, Morgenstern PF, Arko L, Dobri GA, Greenfield JP, Souweidane MM, Tsiouris AJ, Anand VK, Kacker A, Schwartz TH (2018) Preserve or sacrifice the stalk? Endocrinological outcomes, extent of resection, and recurrence rates following endoscopic endonasal resection of craniopharyngiomas. J Neurosurg 1:1-9. DOI: 10.3171/2018.6.JNS18901

27. Ottenhausen M, Rumalla K, La Corte E, et al (2019) Treatment strategies for craniopharyngiomas. J Neurosurg Sci 63:83-87. DOI: 10.23736/S0390-5616.17.04171-6

28. Patel VS, Thamboo A, Quon J, et al (2017) Outcomes after endoscopic endonasal resection of craniopharyngiomas in the pediatric population. World Neurosurg 108:6-14. DOI: 
10.1016/j.wneu.2017.08.058

29. Smee RI, Williams JR, Kwok B, et al (2011) Modern radiotherapy approaches in the management of craniopharyngiomas. J Clin Neurosci 18:613-617. DOI: 10.1016/j.jocn.2010.12.005

30. Sterkenburg AS, Hoffmann A, Gebhardt U, et al (2015) Survival, hypothalamic obesity, and neuropsychological/psychosocial status after childhood-onset craniopharyngioma: newly reported long-term outcomes. Neuro Oncol 17:1029-1038. DOI: 10.1093/neuonc/nov044

31. Van Effenterre R, Boch AL (2002) Craniopharyngioma in adults and children: a study of 122 surgical cases. J Neurosurg 97:3-11. DOI: 10.3171/jns.2002.97.1.0003

32. Varlotto J, DiMaio C, Grassberger C, et al (2016) Multi-modality management of craniopharyngioma: a review of various treatments and their outcomes. Neurooncol Pract 3:173-187. DOI: 10.1093/nop/npv029

33. Wijnen M, van den Heuvel-Eibrink MM, Janssen JAMJL, et al (2017) Very long-term sequelae of craniopharyngioma. Eur J Endocrinol 176:755-767. DOI: 10.1530/EJE-17-0044

34. Yamada S, Fukuhara N, Yamaguchi-Okada M, et al (2018) Therapeutic outcomes of transsphenoidal surgery in pediatric patients with craniopharyngiomas: a single-center study. J Neurosurg Pediatr 21:549-562. DOI: 10.3171/2017.10.PEDS17254

35. Yang I, Sughrue ME, Rutkowski MJ, et al (2010) Craniopharyngioma: a comparison of tumor control with various treatment strategies. Neurosurg Focus 28:E5. DOI: 10.3171/2010.1.FOCUS09307

36. Yano S, Kudo M, Hide T, et al (2016) Quality of life and clinical features of long-term survivors surgically treated for pediatric craniopharyngioma. World Neurosurg 85:153-162. DOI: 10.1016/j.wneu.2015.08.059

\section{Tables}

TABLE 1. Summary of the clinical data of 37 patients with primary craniopharyngiomas resected via EEA 


\begin{tabular}{|c|c|c|}
\hline & $\begin{array}{l}\text { All patients } \\
\mathrm{n}=37\end{array}$ & $\begin{array}{l}\text { intrasellar type } \\
\mathrm{n}=2(5.4 \%)\end{array}$ \\
\hline Surgical procedure EEA & $35(94.6 \%)$ & $2(100 \%)$ \\
\hline EEA + transcranial approach & $2(5.4 \%)$ & 0 \\
\hline Extent of resection, no. (\%) GTR & $33(89.2 \%)$ & $2(100 \%)$ \\
\hline NTR & $3(8.1 \%)$ & 0 \\
\hline STR & $1(2.7 \%)$ & 0 \\
\hline $\begin{array}{l}\text { Intraoperative morphological preservation of stalk, } \\
\text { no. (\%) }\end{array}$ & $10(27.0 \%)$ & $1(50.0 \%)$ \\
\hline \multicolumn{3}{|l|}{ Preoperative visual function, no. (\%) } \\
\hline Normal : Impaired & $7(18.9 \%): 30(81.1 \%)$ & $0: 2(100 \%)$ \\
\hline \multicolumn{3}{|l|}{ Postoperative visual outcomes, no. (\%) } \\
\hline Improved (Preop. Impaired cases) & $23 / 30(76.7 \%)$ & $1 / 2(50.0 \%)$ \\
\hline $\begin{array}{l}\text { Same (Preop. Impaired cases: Preop. Normal } \\
\text { cases) }\end{array}$ & $7 / 30(23.3 \%): 7 / 7(100 \%)$ & $1 / 2(50.0 \%): 0$ \\
\hline Aggravated & 0 & 0 \\
\hline \multicolumn{3}{|l|}{ Preoperative cognitive function, no. (\%) } \\
\hline Normal : Impaired & $28(75.7 \%): 9(24.3 \%)$ & $2(100 \%): 0$ \\
\hline \multicolumn{3}{|l|}{ Postoperative cognitive outcomes, no. (\%) } \\
\hline Improved (Preop. Impaired cases) & $8 / 9(88.9 \%)$ & 0 \\
\hline $\begin{array}{l}\text { Same (Preop. Impaired cases : Preop. Normal } \\
\text { cases) }\end{array}$ & $\begin{array}{l}1 / 9(11.1 \%): 28 / 28 \\
(100 \%)\end{array}$ & \\
\hline Aggravated & 0 & 0 \\
\hline \multicolumn{3}{|l|}{ Endocrinological status, no. (\%) } \\
\hline $\begin{array}{l}\text { Preop. Anterior / Posterior pituitary hormone } \\
\text { dysfunction }\end{array}$ & $32(86.5 \%) / 3(8.1 \%)$ & $2(100 \%) / 0$ \\
\hline $\begin{array}{l}\text { Postop. Anterior / Posterior pituitary hormone } \\
\text { dysfunction }\end{array}$ & $34(91.9 \%) / 33(89.2 \%)$ & $\begin{array}{l}1(50.0 \%) / 1 \\
(50.0 \%)\end{array}$ \\
\hline Preop. BMI, no. (\%) $\mathrm{BMl}<25,25 \leqq \mathrm{BMl}<30,30 \leqq \mathrm{BMI}$ & $\begin{array}{l}33(89.2 \%), 3(8.1 \%), 1 \\
(2.7 \%)\end{array}$ & $2(100 \%), 0,0$ \\
\hline 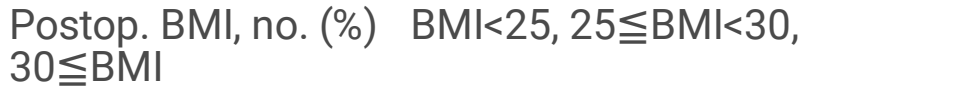 & 30 (81.1\%), 7 (18.9\%), 0 & $2(100 \%), 0,0$ \\
\hline Recurrence rate, no. (\%) Total & $3 / 37(8.1 \%)$ & $0 / 2(0 \%)$ \\
\hline GTR cases & $1 / 33(3.0 \%)$ & $0 / 2(0 \%)$ \\
\hline
\end{tabular}


NTR or NTR + SRS cases

STR case
$1 / 3(33.3 \%)$

$1 / 1(100 \%)$
0

0

* EEA: endoscopic endonasal approach, BMI: Body Mass Index, GTR: Gloss total resection, NTR: Neartotal resection, STR: Subtotal resection, SRS: stereotactic radiosurgery

TABLE 1.(continuation) 


\begin{tabular}{|c|c|c|c|}
\hline $\begin{array}{l}\text { prechiasmatic type } \\
n=4(10.8 \%)\end{array}$ & $\begin{array}{l}\text { Retrochiasmatic type } \\
n=16(43.2 \%)\end{array}$ & $\begin{array}{l}\text { intra-3 } 3^{\text {rd }} \text {-ventricle type } \\
n=12(32.4 \%)\end{array}$ & $\begin{array}{l}\text { large lobulated type } \\
\mathrm{n}=3(8.1 \%)\end{array}$ \\
\hline $4(100 \%)$ & $16(100 \%)$ & $12(100 \%)$ & $1(33.3 \%)$ \\
\hline 0 & 0 & 0 & $2(66.7 \%)$ \\
\hline $4(100 \%)$ & $14(87.5 \%)$ & $12(100 \%)$ & $1(33.3 \%)$ \\
\hline 0 & $2(12.5 \%)$ & 0 & $1(33.3 \%)$ \\
\hline 0 & 0 & 0 & $1(33.3 \%)$ \\
\hline $2(50.0 \%)$ & $4(25.0 \%)$ & $2(16.7 \%)$ & $1(33.3 \%)$ \\
\hline $0: 4(100 \%)$ & $4(25.0 \%): 12(75.0 \%)$ & $3(25.0 \%): 9(75.0 \%)$ & $0: 3(100 \%)$ \\
\hline 4/4 (100\%) & $9 / 12(75.0 \%)$ & $8 / 9(88.9 \%)$ & $1 / 3(33.3 \%)$ \\
\hline $\begin{array}{l}0: 0 \\
0\end{array}$ & $\begin{array}{l}3 / 12(25.0 \%): 4 / 4 \\
(100 \%) \\
0\end{array}$ & $\begin{array}{l}1 / 9(11.1 \%): 3 / 3 \\
(100 \%) \\
0\end{array}$ & $\begin{array}{l}2 / 3(66.7 \%): 0 \\
0\end{array}$ \\
\hline $4(100 \%): 0$ & $15(93.8 \%): 1(6.3 \%)$ & $6(50.0 \%): 6(50.0 \%)$ & 1 (33.3\%) : 2 (66.7\%) \\
\hline 0 & $1 / 1(100 \%)$ & 6/6 (100\%) & $1 / 2(50.0 \%)$ \\
\hline $0: 4 / 4(100 \%)$ & $0 / 1: 15 / 15(100 \%)$ & $0 / 6: 6 / 6(100 \%)$ & $\begin{array}{l}1 / 2(50.0 \%): 1 / 1 \\
(100 \%)\end{array}$ \\
\hline 0 & 0 & 0 & 0 \\
\hline $3(75.0 \%) / 0$ & $14(87.5 \%) / 1(6.3 \%)$ & $10(83.3 \%) / 1(8.3 \%)$ & $3(100 \%) / 1(33.3 \%)$ \\
\hline $\begin{array}{l}3(75.0 \%) / 3 \\
(75.0 \%)\end{array}$ & 16 (100\%) / 15 (93.8\%) & 12 (100\%) / 11 (91.7\%) & $2(66.7 \%) / 3(100 \%)$ \\
\hline $3(75.0 \%), 0,1$ & 14 (87.5\%), 2 (12.5\%), 0 & 11 (91.7\%), 1 (8.3\%), 0 & $3(100 \%), 0,0$ \\
\hline $4(100 \%), 0,0$ & $12(75.0 \%), 4(25.0 \%), 0$ & $\begin{array}{l}10(83.3 \%), 2(16.7 \%) \\
0\end{array}$ & 2 (66.7\%), 1 (33.3\%), 0 \\
\hline $0 / 4(0 \%)$ & $0 / 16(0 \%)$ & $1 / 12(8.3 \%)$ & $2 / 3(66.7 \%)$ \\
\hline $0 / 4(0 \%)$ & $0 / 14(0 \%)$ & $1 / 12(8.3 \%)$ & $0 / 1(0 \%)$ \\
\hline 0 & $0 / 2(0 \%)$ & 0 & 1/1 (100\%) \\
\hline
\end{tabular}


TABLE 2. Summary of detailed histological changes of the surgical procedures and outcomes of primary craniopharyngiomas at a single institute

\begin{tabular}{|c|c|c|}
\hline Outcome Data & $2009-2014(n=28)$ & $2015-2021(n=37)$ \\
\hline Mean clinical follow-up, yrs & 7.4 & 2.7 \\
\hline \multirow[t]{4}{*}{ Surgical procedures } & Interhemispheric approach 14 & EEA 37 \\
\hline & Frontotemporal approach 13 & Frontotemporal approach 1 \\
\hline & TSS 8 (mTSS 3, EEA 5) & Subfrontal approach 1 \\
\hline & Transpetrosal apparoch 4 & \\
\hline Multi-staged surgery, no. (\%) & $11(39.3 \%)$ & $1(2.7 \%)$ \\
\hline \multicolumn{3}{|l|}{ Extent of resection, no. (\%) } \\
\hline GTR & $19(67.9 \%)$ & $33(89.2 \%)$ \\
\hline NTR & $9(32.1 \%)$ & $3(8.1 \%)$ \\
\hline STR & 0 & $1(2.7 \%)$ \\
\hline \multicolumn{3}{|l|}{ Mean KPS score (range) } \\
\hline Preope & $83.0(50-100)$ & $84.9(30-100)$ \\
\hline Postope & $85.3(50-100)$ & $93.2(30-100)$ \\
\hline \multicolumn{3}{|c|}{ Overall clinical outcomes, no. (\%) } \\
\hline Improved & $6(21.4 \%)$ & $24(64.9 \%)$ \\
\hline Same & $22(78.6 \%)$ & $13(35.1 \%)$ \\
\hline Aggravated & 0 & 0 \\
\hline \multicolumn{3}{|l|}{ Recurrence rate, no. (\%) } \\
\hline GTR & $4 / 19(21.1 \%)$ & $1 / 33(3.0 \%)$ \\
\hline NTR or NTR + SRS & $3 / 9(33.3 \%)$ & $1 / 3(33.3 \%)$ \\
\hline STR & 0 & $1 / 1(100 \%)$ \\
\hline
\end{tabular}

* TSS: transsphenoidal surgery, mTSS: microscopic TSS, EEA: endoscopic endonasal approach GTR: Gloss total resection, NTR: Near-total resection, STR: Subtotal resection, KPS: Karnofsky Performance 


\section{Figures}

\section{Surgical strategy based on anatomical sub-classification of primary craniopharyngiomas via EEA}

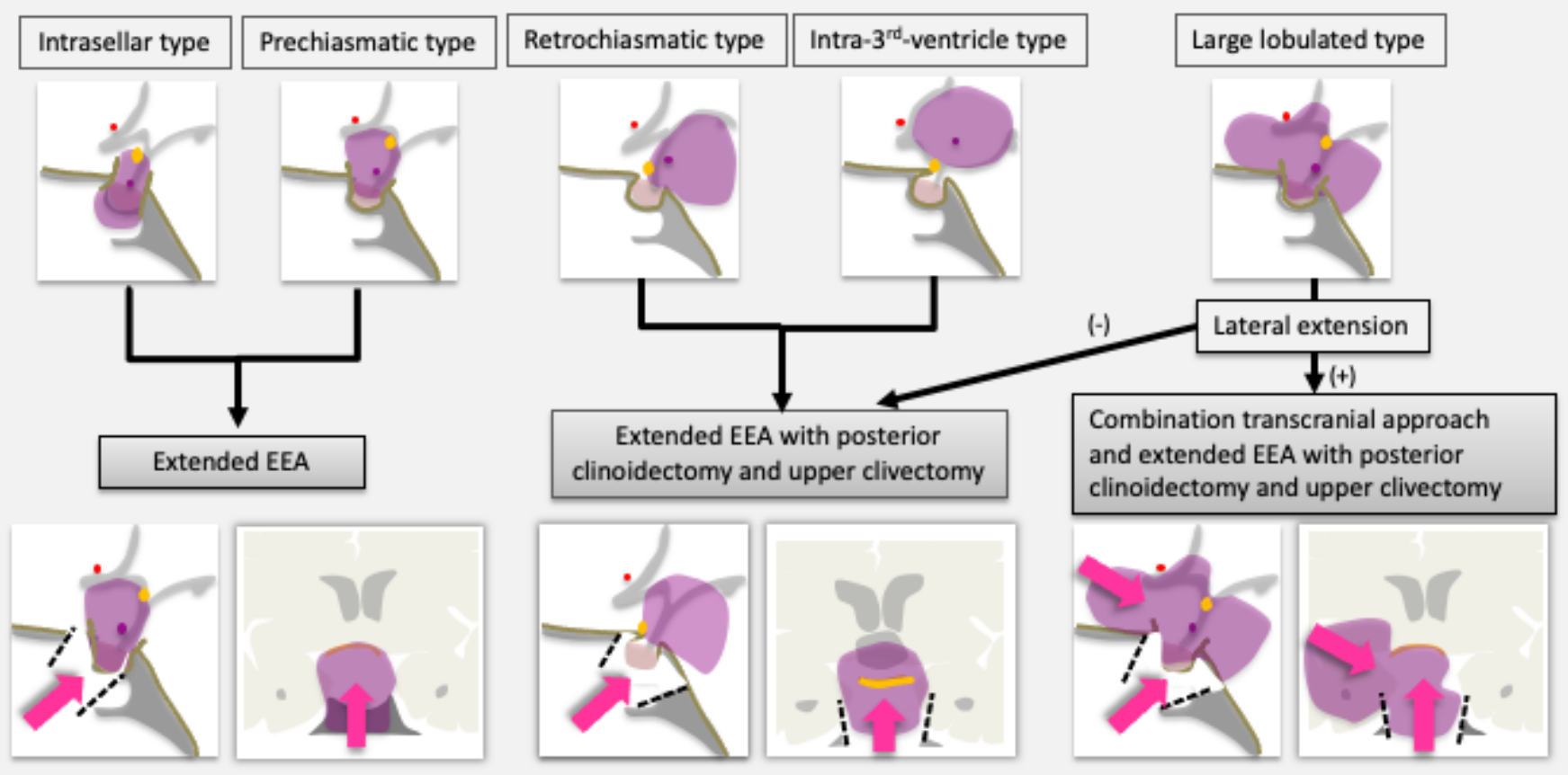

Fig.1

\section{Figure 1}

Surgical strategy based on the anatomical sub-classification of primary craniopharyngiomas via EEA

The intrasellar type originates from the intrasellar part of the pituitary stalk.

The prechiasmatic type originates from the anterior part of the stalk and grows upward. Upward elevation of the optic chiasm and anterior communicating artery is seen.

The retrochiasmatic type originates from the posterior part of the stalk and grows up toward the posterior fossa. The optic chiasm and anterior communicating artery remain in their normal positions.

The intra-third ventricle type originates from the floor of the third ventricle.

Any multi-lobulated lesion exceeding $4 \mathrm{~cm}$ in diameter is defined as a large lobulated-type craniopharyngioma. 
For intrasellar and prechiasmatic types, extended EEA is applied. For retrochiasmatic, intra-third ventricle, and large lobulated types, additional removal of the dorsum sellae, upper clivus and posterior clinoid process is performed. For the large lobulated type with lateral extension, combined surgery using the EEA and transcranial approach is selected.

Red dots indicate the anterior communicating artery.

Yellow dots indicate the optic chiasm.

Purple dots indicate tumor origin. 

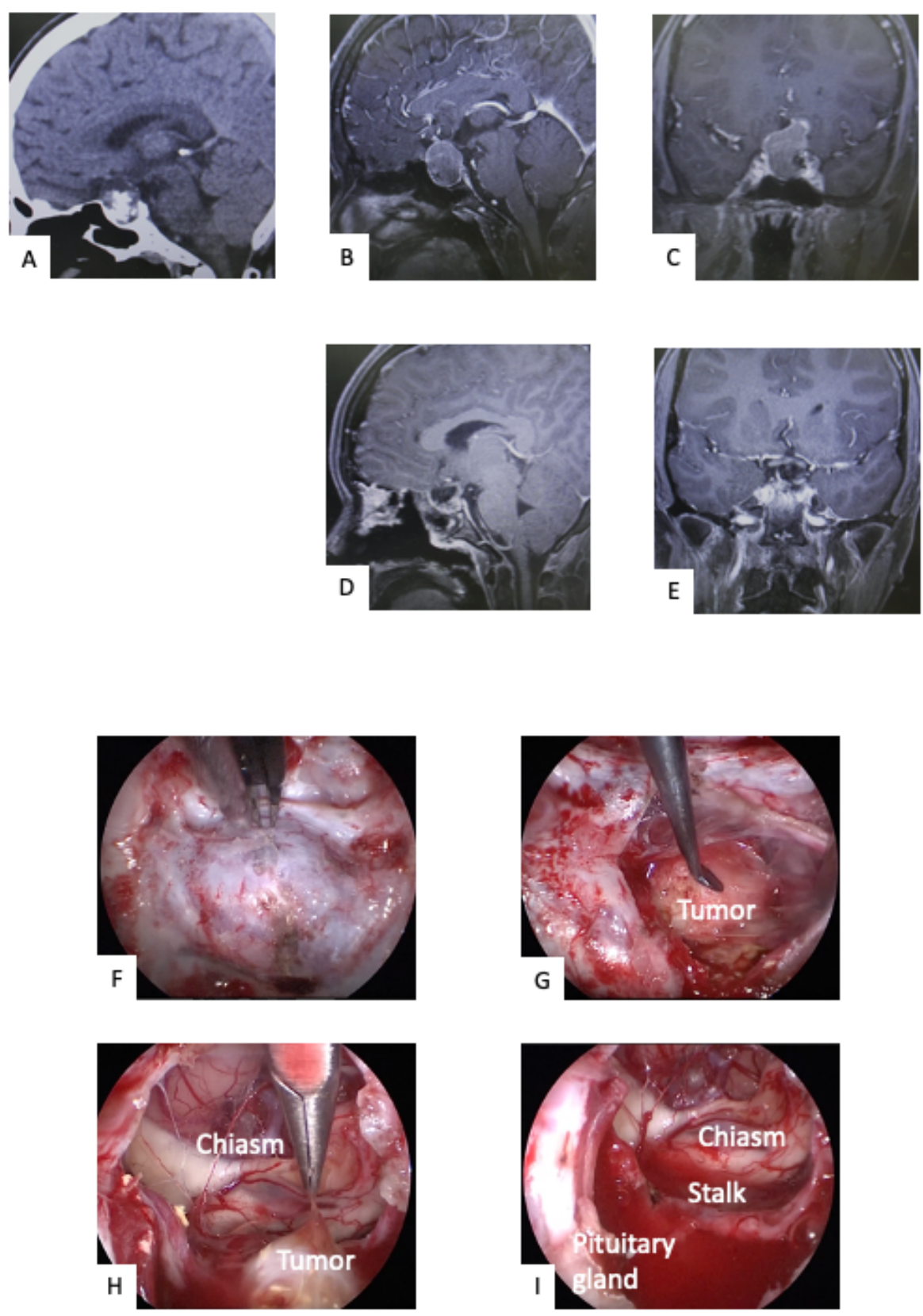

Fig.2

\section{Figure 2}

CT, MRI and intraoperative photographs for Case 1, defined as intrasellar type of craniopharyngioma A-C: Preoperative sagittal-section CT and enhanced T1-weighted MR image in the sagittal and coronal sections show typical findings for the intrasellar type of craniopharyngioma. 
D,E: Postoperative enhanced T1-weighted image in the sagittal and coronal sections. The tumor was totally removed via an extended EEA.

F-l: For the intrasellar type of craniopharyngiomas, the anatomical relationship with the tumor and the surrounding structure is similar to that seen for a pituitary adenoma. The sellar floor is usually enlarged (F). Internal decompression of calcified component of the tumor is performed (G). Since the supra-sellar side of tumor is often covered by extended diaphragm, there is no adhesion with the tumor or the other important blood vessels $(\mathrm{H})$. The tumor totally removed with preserving pituitary gland and stalk (I). 

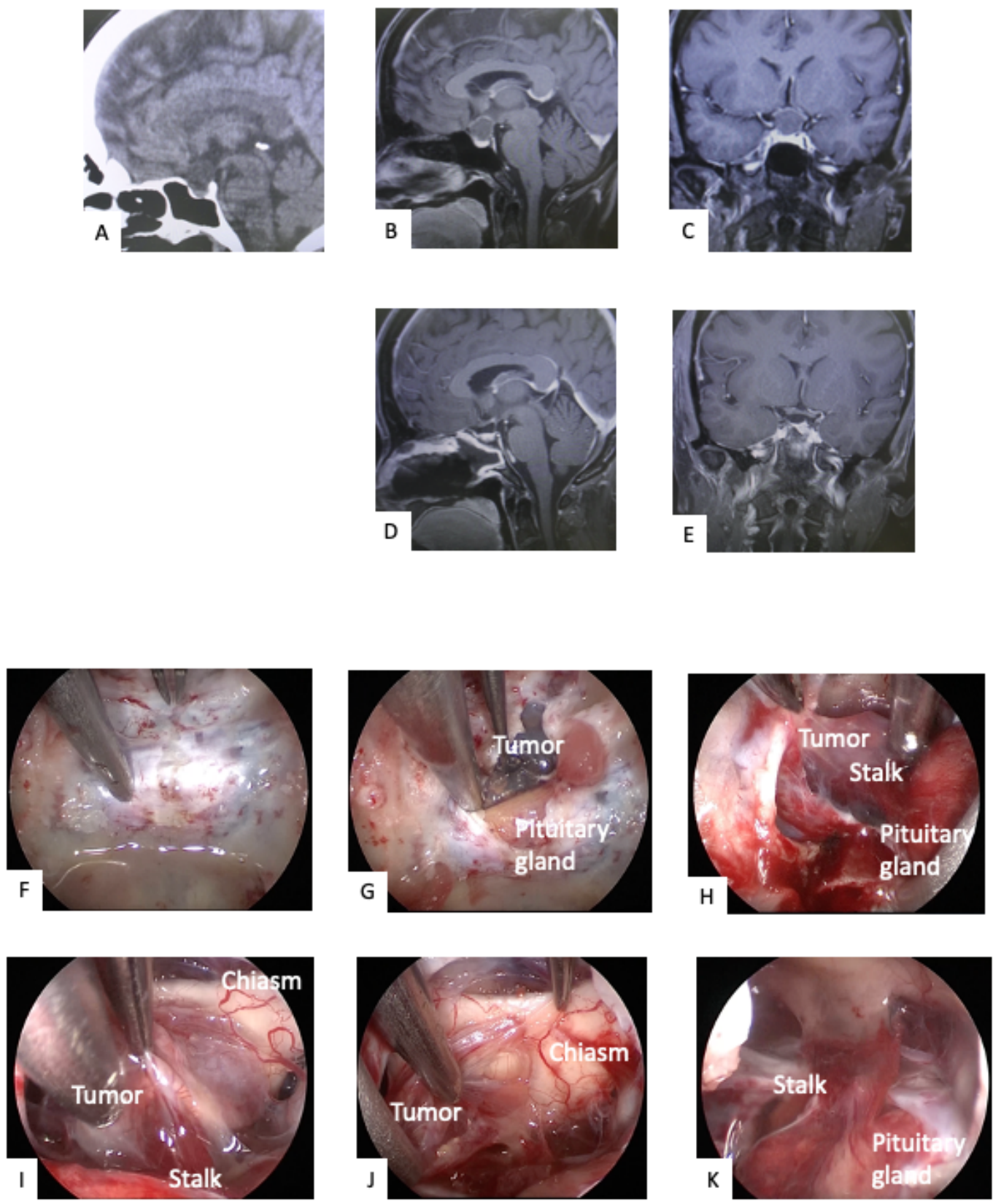

Fig.3

\section{Figure 3}

$\mathrm{CT}, \mathrm{MRI}$ and intraoperative photographs for Case 2, defined as prechiasmatic type of craniopharyngioma A-C: Preoperative sagittal-section CT and enhanced T1-weighted MR image in the sagittal and coronal sections showing elevation of the optic chiasm and the anterior communicating artery. 
D,E: Postoperative enhanced T1-weighted image in the sagittal and coronal sections. The tumor was totally removed via an extended EEA.

F-K: Bone was removed from the sellar floor to the planum sphenoidale (F). The normal pituitary gland was identified at the bottom of the sellar floor $(G)$. The pituitary gland is detached from the medial wall of the right cavernous sinus and transposed to the left side $(\mathrm{H})$. We carefully dissected the tumor off of any adjacent critical neurovascular structures, including the stalk and optic chiasm (I). Since the tumor did not invade all parts of the stalk, we were able to remove the tumor with preserving the stalk (K). 

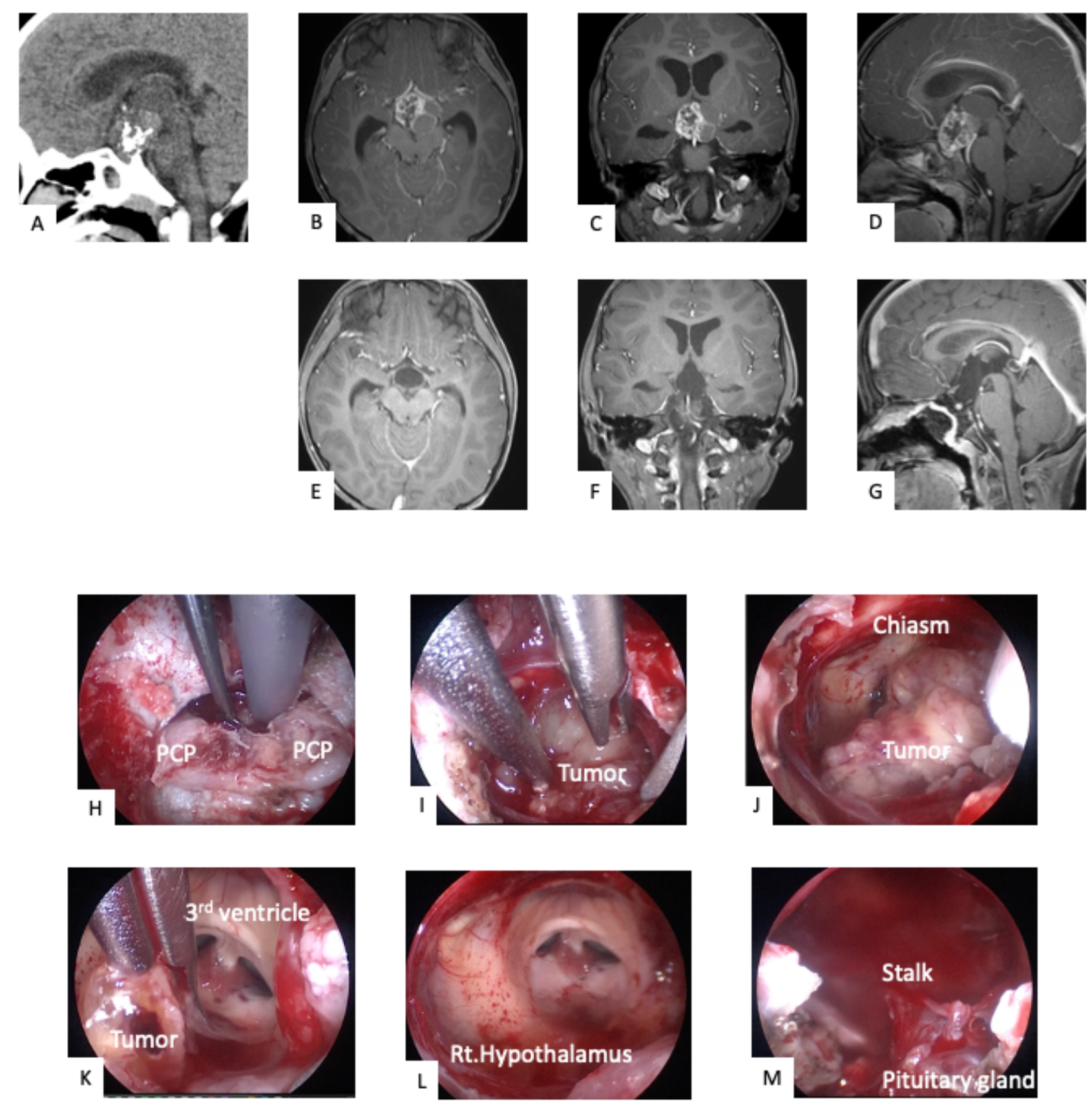

Fig.4

\section{Figure 4}

$\mathrm{CT}, \mathrm{MRI}$ and intraoperative photographs for Case 3, involving retrochiasmatic-type craniopharyngioma A-D) Preoperative sagittal-section CT and enhanced T1-weighted images in the axial, coronal and sagittal sections show findings of retrochiasmatic-type craniopharyngioma with calcification. The anterior communicating artery and optic chiasm are not elevated. 
E-G) Postoperative contrast-enhanced T1-weighted images in the axial, coronal and sagittal sections. The tumor is totally removed via EEA.

$\mathrm{H}-\mathrm{M}$ ) After slightly raising the normal pituitary gland, the upper clivus, dorsum sellae and bilateral posterior clinoid processes are removed $(\mathrm{H})$. Tumor is confirmed after the normal pituitary gland appears displaced (I). Internal decompression of the tumor is performed $(\mathrm{J})$. Tumor capsule is removed from the wall of the third ventricle $(K)$. The tumor is completely removed $(L)$. The pituitary stalk is preserved morphologically $(K)$.

PCP: posterior clinoid process. 

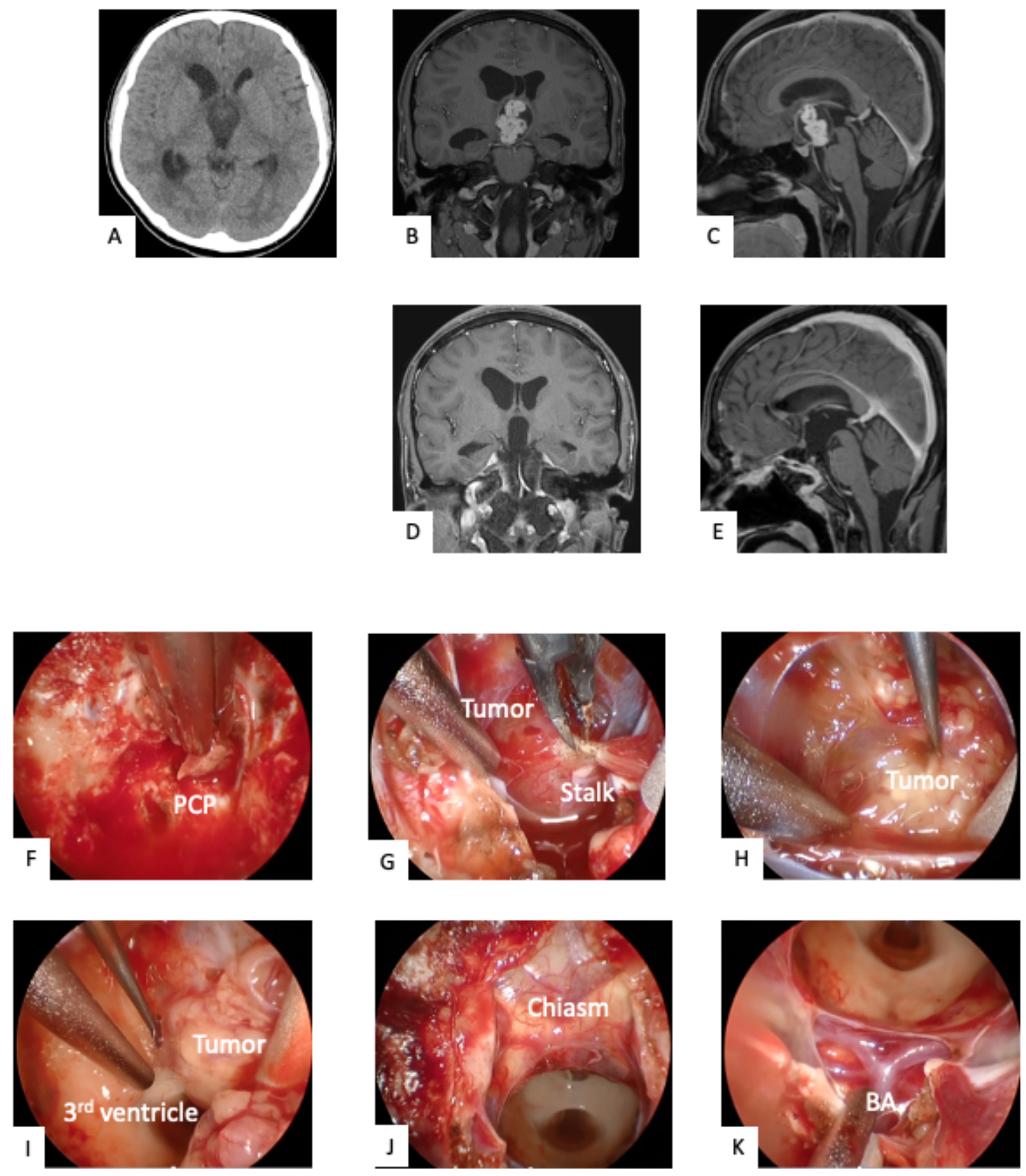

Fig.5

\section{Figure 5}

CT, MRI and intraoperative photographs for Case 4, defined as intra-third ventricle craniopharyngioma A-C) Preoperative axial-section CT and enhanced T1-weighted imaging in the coronal and sagittal sections show enlargement of the third ventricle, a typical finding for the intra-third ventricle type. 
D, E) Postoperative enhanced T1-weighted imaging in the coronal and sagittal sections. The tumor has been totally removed via EEA.

F-M) Bone removal has been performed from the bottom of the sellae turcica to the tuberculum sellae (F). Additional bony removal of the dorsum sellae, upper clivus and bilateral posterior clinoid processes is performed $(G)$. The pituitary gland is detached from the medial wall of the right cavernous sinus and transposed to the left side $(\mathrm{H})$. Tumor is confirmed around the infundibular recess, making the pituitary stalk difficult to preserve. Coagulation is performed and the stalk is cut $(\mathrm{I})$. Internal decompression of the tumor is started $(J)$. The tumor capsule is peeled from the wall of the third ventricle $(K)$. The tumor is completely removed $(L, M)$.

PCP: posterior clinoid process, BA: basilar artery 

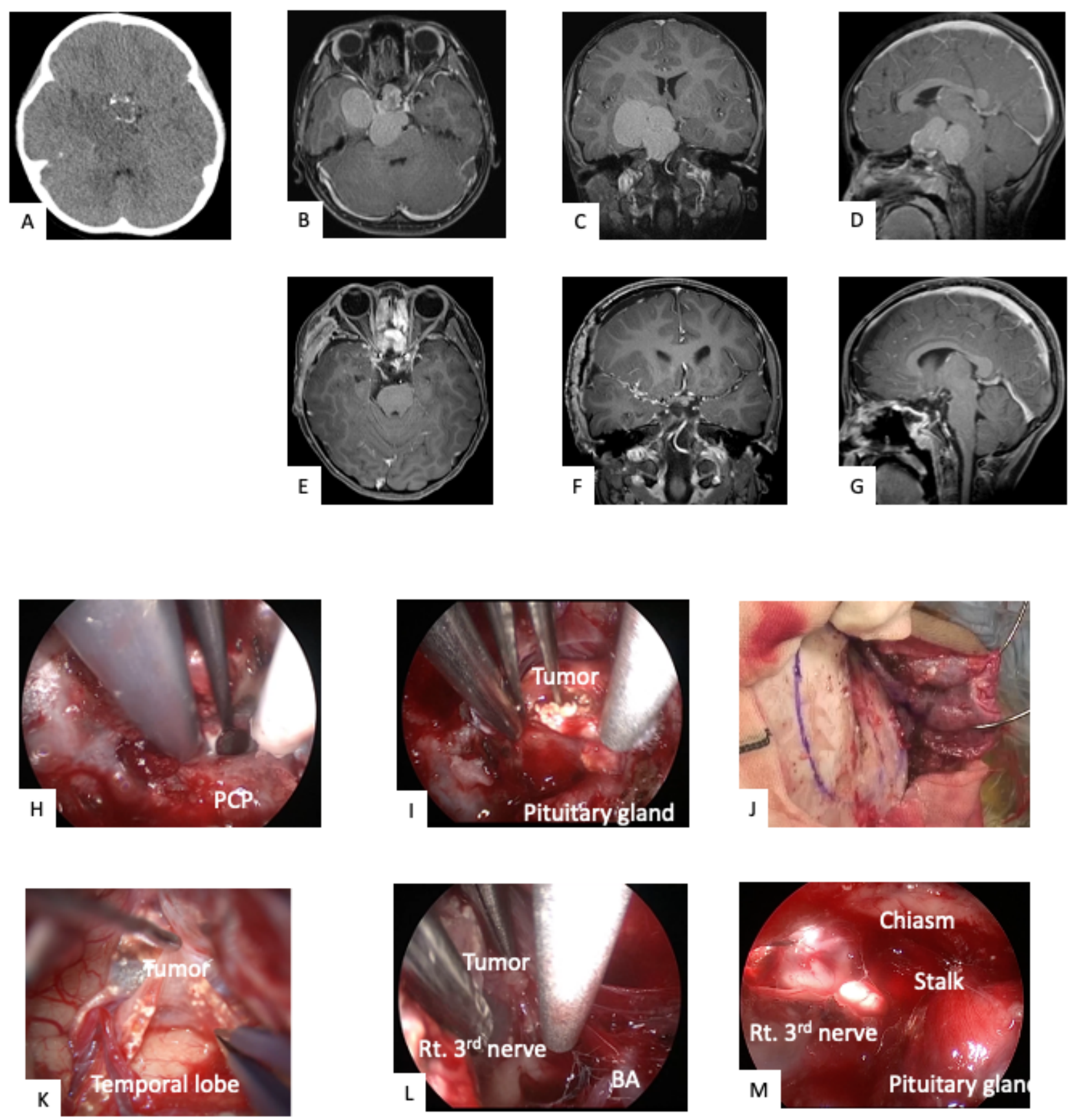

Fig.6

\section{Figure 6}

CT, MRI and intraoperative photographs for Case 5, defined as large, lobulated type with lateral extension A-D) Preoperative axial-section CT and enhanced T1-weighted images in the axial, coronal and sagittal sections show large, lobulated-type craniopharyngioma with lateral extension. 
E-G) Postoperative enhanced T1-weighted images in the axial, coronal and sagittal sections. The tumor has been totally removed via a combination of the EEA and frontotemporal approach.

$\mathrm{H}-\mathrm{M}$ ) Bony removal of the dorsum sellae, upper clivus and bilateral posterior clinoid processes is performed via EEA $(\mathrm{H})$. After the pituitary gland is displaced to the left, the center part of the lesion inside the circle of Willis is removed (I). Right frontotemporal craniotomy is performed $(\mathrm{J})$. After the Sylvian fissure is opened, the tumor capsule is detached from the deep Sylvian vein and brain surface via a transcranial approach $(\mathrm{K})$. The tumor is peeled from the oculomotor nerve, and the posterior cystic component of the tumor is removed via EEA $(\mathrm{L})$. Finally, the tumor is completely removed with preservation of the pituitary stalk (M).

\section{Supplementary Files}

This is a list of supplementary files associated with this preprint. Click to download.

- video1.mp4

- video2.mp4 